Public Abstract

First Name:Sachin

Middle Name:S

Last Name:Bhusari

Adviser's First Name:Eric

Adviser's Last Name:Antoniou

Co-Adviser's First Name:

Co-Adviser's Last Name:

Graduation Term:FS 2006

Department:Animal Sciences

Degree:PhD

\title{
Title:EFFECTS OF FESCUE TOXICOSIS AND CHRONIC HEAT STRESS ON MURINE HEPATIC GENE EXPRESSION
}

Fescue toxicosis affects domestic animals grazing fescue pasture infected with an endophytic fungus. Fescue toxicosis causes losses amounting to $\$ 600$ million to beef cattle industry annually. Signs of fescue toxicosis include increased body temperature, and respiration rate, and decreased milk yield and reproductive performance. Fescue toxicosis is exacerbated by elevated ambient temperatures as seen in Missouri summers. Little is known about gene expression changes involved in fescue toxicosis. Mice were used to study effects of fescue toxicosis, heat stress and combination of both on liver gene expression. Mice fed endophyte-infected fescue diet at ambient temperatures resulted in change in expression of genes involved in sex-steroid pathway, lipid and cholesterol metabolism. Anti-oxidant gene expression changes occurred predominantly in mice exposed to heat stress.

Interestingly, gene expression changes involved in detoxification pathway were seen only in mice exposed to combination of endophyte-infected diet and heat stress. Thus, these results indicate that animals exposed to combination of endophyte-infected fescue diet and heat stress exhibit a unique genetic response. Gene expression changes identified in mouse liver due to endophyte-infected diet, heat stress, and combination of both might help to understand some of the biological pathways by which fescue toxicosis and heat stress affect animals. 